\title{
Evaluation of Accuracy of Cell Count in Ascitic Fluid in Automated Cell Counter and Comparison with Manual Count
}

\author{
Kusum Agrawal ${ }^{1}$, Sandhya Gulati ${ }^{2}$, Gaurav Gupta $^{3}$, Nidhi Sharma $^{4}$, Ajay Yadav $^{5}$ \\ ${ }^{1}$ Final year Resident, ${ }^{2}$ Professor, ${ }^{4}$ Assistant professor, ${ }^{5}$ Professor \& Head, Department of Pathology, \\ ${ }^{3}$ Associate Professor, Department of Gastroenterology, \\ S.M.S. Medical College \& Hospital, Jaipur, Rajasthan, India.
}

\begin{abstract}
Introduction: Correct cell enumeration and differential analysis of body fluids are important in the diagnosis and management of several diseases. Currently, microscopic analysis is still considered the "gold standard". The introduction of automated analysis has reduced interoperator variability, improved turnaround time and precision. The present study was designed to determine the shelf life and appropriate anticoagulant for automated cell counter and to compare manual and automated cell count in ascitic fluid.

Methods: We examined total 250 ascitic fluid samples. Total and differential cell counting of each sample has been conducted with the Sysmex XT-4000i and the manual method (Neubauer chamber). Linearity, carryover, precision and correlation were also assessed.

Results: The precision analysis of random sample with high cell count indicated that the Sysmex XT-4000i demonstrated good precision for RBC, WBC, MN\#, PMN\# at 0 and 6 hour in all vials resulted in $\mathrm{CVs}<0.012 \%$. Carryover effect was negligible for both WBC and RBC count in ascitic fluid. It never exceeded $0.180 \%$. Sysmex XT-4000i showed significant positive correlation for WBC count in plain vial $(r=0.984$, $p<0.001 s)$, EDTA vial $(r=0.998, p<0.001 s)$, PT vial $(r=0.958$,
\end{abstract}

\section{INTRODUCTION}

Body fluid cell counts are a routine clinical laboratory test that provides valuable information for diagnosing and treating various medical conditions. ${ }^{1}$ Manual microscopy, mostly based on total cell count and cytocentrifuged differential count is still considered the gold standard for body fluid analysis. Manual microscopy carries several important technical and analytical drawbacks such as inherent complexity, reduced turnaround time, the need for skilled and specialized personnel along with large interobserver variability and low precision. ${ }^{2}$

The use of automated hemocytometric analyzers has gained acceptance as an alternative method to manual microscopy for initial screening of abnormalities in BFs. ${ }^{3}$ Automation offers potential benefits of improved accuracy, precision, laboratory efficiency and cost effectiveness. ${ }^{4}$

Sysmex XT-4000i is the fully automated analyzer developed by Sysmex containing a body fluid specific mode. The analyzer applies proven impedance and fluorescence flow cytometry ensuring an accurate body fluid count. It provides expanded sensitivity and linearity; WBC and RBC counts reportable to 3 decimal places. Seven body fluid reportable parameters are: WBC-BF, RBC-BF, TC-BF, MN\%, MN\#, PMN\%, PMN\#. No sample pretreatment, no additional reagents and no additional $p<0.001 \mathrm{~s}$ ) at 0 hour and those kept at $4^{\circ} \mathrm{C}$ and reanalyzed at 6 hour.

Conclusion: With some limitations, total and differential cell counts in ascitic fluid can be reliably determined using the Sysmex XT-4000i instrument.

Keywords: Ascitic fluid, Neubauer chamber, Sysmex XT$4000 \mathrm{i}$, cell count.

\section{${ }^{*}$ Correspondence to:}

Dr. Kusum Agrawal,

Final Year Resident, Department of Pathology,

S.M.S. Medical College \& Hospital, Jaipur, Rajasthan, India.

Article History:

Received: 04-06-2016, Revised: 11-06-2016, Accepted: 05-07-2016

\begin{tabular}{|l|r|}
\hline \multicolumn{2}{|c|}{ Access this article online } \\
\hline Website: & Quick Response code \\
www.ijmrp.com & \\
\hline DOI: & \\
10.21276/ijmrp.2016.2.4.029 & \\
\hline
\end{tabular}

quality control material required. It has benefits of improved productivity, decreased turnaround time and decreased manual technical intervention. ${ }^{5}$

The aims of our study were to determine the shelf life and appropriate anticoagulant for automated cell counter and comparison of automated cell count with manual count.

\section{MATERIAL AND METHODS}

Study design: This was a laboratory based validational analytic type of observational study conducted in HLA and Advanced Hematology Lab, Department of pathology, SMS Medical College, Jaipur, Rajasthan.

Study population: All cases presenting with ascites from June 2014 to December 2015 were studied. We examined 250 ascitic fluid samples for our study.

Inclusion criteria: Freshly obtained all ascitic fluid samples.

Exclusion criteria: Those patients who did not give consent, there is delay in transport of samples.

\section{METHODOLOGY}

Ascitic fluid collection: Ascitic fluid was collected by abdominal paracentesis under aseptic conditions.Ascitic fluid sample was 
collected in plain tubes, in tubes containing EDTA as anticoagulant and in tubes containing Na-citrate as anticoagulant. WBC count was determined by both traditional method with a light microscope in a manual counting chamber (Neubauer chamber) and also with automated cell counter (Sysmex XT-4000i). Both total leukocyte count and differential cell count were determined. Samples were analysed at 0 hour and then stored at $4^{\circ} \mathrm{C}$ and reanalyzed at 6 hours.

\section{Manual method}

Neubauer counting chamber were used to perform manual RBC and nucleated cell counts. RBC count was determined by counting the cells in the standard 5 small squares in the centre square on each side of the chamber and the nucleated cells were counted in the 4 larger corner squares on each side of the chamber. The standard Neubauer calculation formula was used to determine the number of cells per cubic $\mathrm{mm}^{6}$

\section{Automated cell counter method}

For WBC count by the automated method, the samples in plain vial, EDTA vial, Na-citrate vial were run in the automated hematology analyzer Sysmex XT- 4000i and values were noted. Automated system module Sysmex XT-4000i uses direct current (DC) and radiofrequency impedance for RBC count and fluorescence flow cytometry for WBC.

\section{Precision}

Within run precision of the Sysmex XT-4000i instrument for both high and low cell counts were analyzed ten times consecutively within a day. The results were expressed as the CV\% at different mean cell concentrations.

\section{Carryover}

A sample with a high cell count $(\mathrm{H} 1, \mathrm{H} 2, \mathrm{H} 3)$ was measured 3 times followed by three measurements of sample with a low cell count (L1, L2, L3). Carryover\% was calculated as follows: $\{(\mathrm{L} 1-\mathrm{L} 3)$ / $(\mathrm{H} 3-\mathrm{L} 3)\} \times 100 .^{3}$

\section{Linearity}

This was verified for total WBC count, mononuclear cells, polymorphonuclear cells and RBC count by running a ascitic fluid five times in dilution. Then results of cell counts compared with expected cell counts.

\section{Statistical analysis}

Pearson's correlation coefficient were calculated between WBC and differential counts generated by Sysmex XT-4000i hematology analyzer and those determined by manual microscopic method. Agreement between the methods was determined using Passing-Bablok regression analysis.

Table 1a: Precision Analysis Of Random Sample With High Cell Count In (Plain Vial) At 0 And 6 Hour

\begin{tabular}{ccccccccccccc}
\hline \multicolumn{1}{c}{ PLAIN VIAL AT 0 HOUR } & \multicolumn{4}{c}{ PLAIN VIAL AT 6 HOUR } \\
\hline $\begin{array}{c}\text { SAMPLE } \\
\text { RUN }\end{array}$ & S- & SBC & S-RBC & MN\# & PMN\# & MN\% & PMN\% & $\begin{array}{c}\text { S- } \\
\text { S- }\end{array}$ & MN\# & PMN\# & MN\% & PMN\% \\
$\mathbf{1}$ & 1.151 & 0.009 & 0.478 & 0.67 & 41.5 & 58.5 & 0.627 & 0.008 & 0.361 & 0.266 & 57.6 & 42.4 \\
$\mathbf{2}$ & 1.125 & 0.009 & 0.448 & 0.68 & 39.8 & 60.2 & 0.644 & 0.008 & 0.328 & 0.316 & 50.9 & 49.1 \\
$\mathbf{3}$ & 1.142 & 0.008 & 0.467 & 0.68 & 40.9 & 59.1 & 0.623 & 0.009 & 0.346 & 0.277 & 55.5 & 44.5 \\
$\mathbf{4}$ & 1.066 & 0.009 & 0.417 & 0.65 & 39.1 & 60.9 & 0.614 & 0.009 & 0.322 & 0.292 & 52.4 & 47.6 \\
$\mathbf{5}$ & 0.999 & 0.009 & 0.376 & 0.62 & 37.6 & 62.4 & 0.727 & 0.01 & 0.359 & 0.368 & 49.4 & 50.6 \\
$\mathbf{6}$ & 0.966 & 0.009 & 0.369 & 0.6 & 38.2 & 61.8 & 0.702 & 0.009 & 0.33 & 0.372 & 47 & 53 \\
$\mathbf{7}$ & 1.014 & 0.008 & 0.375 & 0.64 & 37 & 63 & 0.739 & 0.009 & 0.362 & 0.377 & 49 & 51 \\
$\mathbf{8}$ & 0.994 & 0.009 & 0.374 & 0.62 & 37.6 & 62.4 & 0.811 & 0.009 & 0.357 & 0.454 & 44 & 56 \\
$\mathbf{9}$ & 0.959 & 0.009 & 0.366 & 0.59 & 38.2 & 61.8 & 0.895 & 0.01 & 0.405 & 0.49 & 45.3 & 54.7 \\
$\mathbf{1 0}$ & 0.962 & 0.009 & 0.353 & 0.61 & 36.7 & 63.3 & 0.855 & 0.009 & 0.365 & 0.49 & 42.7 & 57.3 \\
MEAN & 1.04 & 0.01 & 0.40 & 0.64 & 38.66 & 61.34 & 0.72 & 0.01 & 0.35 & 0.37 & 49.38 & 50.62 \\
SD & 0.08 & 0.00 & 0.05 & 0.03 & 1.63 & 1.63 & 0.10 & 0.00 & 0.02 & 0.08 & 4.86 & 4.86 \\
CV\%* & 0.01 & 0.00 & 0.00 & 0.00 & 2.65 & 2.65 & 0.01 & 0.00 & 0.00 & 0.01 & 23.61 & 23.61 \\
\hline
\end{tabular}

${ }^{*} \mathrm{CV}=$ Coefficient of variation

Table 1b: Precision Analysis Of Random Sample With High Cell Count In (EDTA Vial) At 0 And 6 Hour

\begin{tabular}{ccccccccccccc}
\hline \multicolumn{1}{c}{ EDTA VIAL AT 0 HOUR } & \multicolumn{5}{c}{ EDTA VIAL AT 6 HOUR } \\
\hline SAMPLE & S- & S- & MN\# & PMN\# & MN\% & PMN\% & S- & S- & MN\# & PMN\# & MN\% & PMN\% \\
RUN & WBC & RBC & & & & & WBC & RBC & & & & \\
$\mathbf{1}$ & 1.31 & 0.009 & 0.548 & 0.76 & 41.8 & 58.2 & 0.626 & 0.008 & 0.182 & 0.444 & 29.1 & 70.9 \\
$\mathbf{2}$ & 1.2 & 0.008 & 0.456 & 0.74 & 38.1 & 61.9 & 0.912 & 0.008 & 0.228 & 0.684 & 25 & 75 \\
$\mathbf{3}$ & 1.19 & 0.008 & 0.385 & 0.81 & 32.3 & 67.7 & 0.989 & 0.008 & 0.24 & 0.749 & 24.3 & 75.7 \\
$\mathbf{4}$ & 1.17 & 0.009 & 0.341 & 0.83 & 29.2 & 70.8 & 0.865 & 0.008 & 0.211 & 0.654 & 24.4 & 75.6 \\
$\mathbf{5}$ & 1.12 & 0.008 & 0.297 & 0.83 & 26.4 & 73.6 & 0.913 & 0.009 & 0.203 & 0.71 & 22.2 & 77.8 \\
$\mathbf{6}$ & 1.12 & 0.009 & 0.306 & 0.82 & 27.2 & 72.8 & 0.953 & 0.008 & 0.21 & 0.743 & 22 & 78 \\
$\mathbf{7}$ & 1.15 & 0.009 & 0.257 & 0.89 & 22.4 & 77.6 & 0.958 & 0.008 & 0.207 & 0.751 & 21.6 & 78.4 \\
$\mathbf{8}$ & 1.11 & 0.008 & 0.256 & 0.85 & 23.2 & 76.8 & 0.955 & 0.009 & 0.216 & 0.739 & 22.6 & 77.4 \\
$\mathbf{9}$ & 1.09 & 0.009 & 0.231 & 0.86 & 21.1 & 78.9 & 0.799 & 0.009 & 0.197 & 0.602 & 24.7 & 75.3 \\
$\mathbf{1 0}$ & 1.07 & 0.009 & 0.245 & 0.82 & 22.9 & 77.1 & 0.926 & 0.009 & 0.196 & 0.73 & 21.2 & 78.8 \\
MEAN & 1.153 & 0.009 & 0.332 & 0.821 & 28.460 & 71.540 & 0.890 & 0.008 & 0.209 & 0.681 & 23.710 & 76.290 \\
SD & 0.070 & 0.001 & 0.103 & 0.044 & 7.004 & 7.004 & 0.107 & 0.001 & 0.017 & 0.096 & 2.350 & 2.350 \\
CV\% & 0.005 & 0.000 & 0.011 & 0.002 & 49.054 & 49.054 & 0.012 & 0.000 & 0.000 & 0.009 & 5.523 & 5.523 \\
\hline
\end{tabular}


Table 1c: Precision Analysis Of Random Sample With High Cell Count In (PT Vial) At 0 And 6 Hour

\begin{tabular}{|c|c|c|c|c|c|c|c|c|c|c|c|c|}
\hline \multirow[b]{2}{*}{$\begin{array}{l}\text { SAMPLE } \\
\text { RUN }\end{array}$} & \multicolumn{6}{|c|}{ PT VIAL AT 0 HOUR } & \multicolumn{6}{|c|}{ PT VIAL AT 6 HOUR } \\
\hline & $\begin{array}{c}\text { S- } \\
\text { WBC }\end{array}$ & $\begin{array}{c}\text { S- } \\
\text { RBC }\end{array}$ & MN\# & PMN\# & MN\% & PMN\% & $\begin{array}{c}\text { S- } \\
\text { WBC }\end{array}$ & $\begin{array}{c}\text { S- } \\
\text { RBC }\end{array}$ & MN\# & PMN\# & MN\% & PMN\% \\
\hline 1 & 0.93 & 0.008 & 0.379 & 0.56 & 40.6 & 59.4 & 0.884 & 0.007 & 0.343 & 0.541 & 38.8 & 61.2 \\
\hline 2 & 0.97 & 0.008 & 0.385 & 0.58 & 39.9 & 60.1 & 0.897 & 0.008 & 0.339 & 0.558 & 37.8 & 62.2 \\
\hline 3 & 1.03 & 0.007 & 0.397 & 0.64 & 38.5 & 61.5 & 0.994 & 0.008 & 0.349 & 0.645 & 35.1 & 64.9 \\
\hline 4 & 1.04 & 0.008 & 0.353 & 0.69 & 34 & 66 & 0.804 & 0.006 & 0.281 & 0.523 & 35 & 65 \\
\hline 5 & 1.04 & 0.007 & 0.369 & 0.68 & 35.3 & 64.7 & 0.964 & 0.007 & 0.325 & 0.556 & 31.8 & 68.2 \\
\hline 6 & 1.02 & 0.007 & 0.324 & 0.69 & 31.9 & 68.1 & 0.98 & 0.007 & 0.332 & 0.582 & 32.8 & 67.2 \\
\hline 7 & 1.02 & 0.007 & 0.322 & 0.7 & 31.4 & 68.6 & 0.811 & 0.007 & 0.321 & 0.634 & 38.4 & 61.6 \\
\hline 8 & 0.96 & 0.008 & 0.307 & 0.66 & 31.8 & 68.2 & 0.895 & 0.008 & 0.354 & 0.672 & 39.2 & 60.8 \\
\hline 9 & 0.98 & 0.007 & 0.322 & 0.66 & 32.9 & 67.1 & 0.855 & 0.008 & 0.347 & 0.575 & 30.5 & 69.5 \\
\hline 10 & 1.05 & 0.007 & 0.32 & 0.73 & 30.5 & 69.5 & 0.84 & 0.008 & 0.327 & 0.701 & 34.5 & 65.5 \\
\hline MEAN & 1.005 & 0.007 & 0.348 & 0.657 & 34.680 & 65.320 & 0.892 & 0.007 & 0.332 & 0.599 & 35.390 & 64.610 \\
\hline SD & 0.040 & 0.001 & 0.033 & 0.054 & 3.729 & 3.729 & 0.068 & 0.001 & 0.021 & 0.060 & 3.083 & 3.083 \\
\hline CV\% & 0.002 & 0.000 & 0.001 & 0.003 & 13.906 & 13.906 & 0.005 & 0.000 & 0.000 & 0.004 & 9.505 & 9.505 \\
\hline
\end{tabular}

Table 1d: Precision Analysis Of Random Sample With Low Cell Count In (EDTA Vial) At 0 And 6 Hour

\begin{tabular}{ccccccccccccc}
\hline \multicolumn{1}{c}{ EDTA VIAL AT 0 HOUR } & \multicolumn{4}{c}{ EDTA VIAL AT 6 HOUR } \\
\hline SAMPLE & $\begin{array}{c}\text { S- } \\
\text { RUN }\end{array}$ & WBC & RBC & MN\# & PMN\# & MN\% & PMN\% & $\begin{array}{c}\text { S- } \\
\text { S- }\end{array}$ & MN\# & PMN\# & MN\% & PMN\% \\
$\mathbf{1}$ & 0.08 & 0 & 0.073 & 0.00 & 94.8 & 5.2 & 0.194 & 0 & 0.147 & 0.047 & 75.8 & 24.2 \\
$\mathbf{2}$ & 0.08 & 0 & 0.076 & 0.01 & 92.7 & 7.3 & 0.191 & 0 & 0.131 & 0.06 & 68.6 & 31.4 \\
$\mathbf{3}$ & 0.07 & 0 & 0.066 & 0.00 & 95.7 & 4.3 & 0.201 & 0 & 0.153 & 0.048 & 76.1 & 23.9 \\
$\mathbf{4}$ & 0.08 & 0 & 0.072 & 0.01 & 92.3 & 7.7 & 0.182 & 0 & 0.136 & 0.046 & 74.7 & 25.3 \\
$\mathbf{5}$ & 0.09 & 0 & 0.083 & 0.01 & 90.2 & 9.8 & 0.207 & 0 & 0.137 & 0.07 & 66.2 & 33.8 \\
$\mathbf{6}$ & 0.09 & 0 & 0.061 & 0.02 & 71.8 & 28.2 & 0.206 & 0 & 0.132 & 0.074 & 64.1 & 35.9 \\
$\mathbf{7}$ & 0.09 & 0 & 0.077 & 0.01 & 86.5 & 13.5 & 0.221 & 0 & 0.134 & 0.087 & 60.6 & 39.4 \\
$\mathbf{8}$ & 0.10 & 0 & 0.086 & 0.02 & 82.7 & 17.3 & 0.162 & 0 & 0.144 & 0.018 & 88.9 & 11.1 \\
$\mathbf{9}$ & 0.12 & 0 & 0.109 & 0.01 & 94.8 & 5.2 & 0.238 & 0 & 0.141 & 0.097 & 59.2 & 40.8 \\
$\mathbf{1 0}$ & 0.13 & 0 & 0.12 & 0.01 & 90.9 & 9.1 & 0.247 & 0 & 0.142 & 0.105 & 57.5 & 42.5 \\
MEAN & 0.09 & 0.00 & 0.08 & 0.01 & 89.24 & 10.76 & 0.20 & 0.00 & 0.14 & 0.07 & 69.17 & 30.83 \\
SD & 0.02 & 0.00 & 0.02 & 0.01 & 7.33 & 7.33 & 0.03 & 0.00 & 0.01 & 0.03 & 9.75 & 9.75 \\
CV\% & 0.00 & 0.00 & 0.00 & 0.00 & 53.67 & 53.67 & 0.00 & 0.00 & 0.00 & 0.00 & 95.08 & 95.08 \\
\hline
\end{tabular}

\section{RESULTS}

Precision

The precision analysis of random sample with high cell count indicated that the Sysmex XT-4000i demonstrated good precision for RBC, WBC, MN\#, PMN\# at 0 and 6 hour in all vials resulted in CVs $<0.012 \%$.

Results of precision of low cell count were excellent in EDTA vial with CVs being $0 \%$ for RBC, TLC, MN\#, PMN\# at 0 and 6 hour. (Table 1a-1d)

\section{Carryover}

Carryover effect on the Sysmex XT-4000i BF mode was negligible for both WBC and RBC in ascitic fluid. It never exceeded $0.180 \%$ for WBC count. For RBC carryover results were $0 \%$ in all vials at 0 and 6 hour. (Table 2)

Linearity

Sysmex XT-4000i presented an excellent correlation between expected and observed values $(r=0.962)$ in plain vial and $(r=0.960)$ in PT vial for MN. (Fig 1, 2)

Table 2: CARRYOVER Analysis

\begin{tabular}{|c|c|c|c|c|c|c|c|c|c|c|c|c|}
\hline \multirow[b]{3}{*}{ RUN NO. } & \multicolumn{4}{|c|}{ PLAIN VIAL } & \multicolumn{4}{|c|}{ EDTA VIAL } & \multicolumn{4}{|c|}{ PT VIAL } \\
\hline & \multicolumn{2}{|c|}{ AT 0 HOUR } & \multicolumn{2}{|c|}{ AT 6 HOUR } & \multicolumn{2}{|c|}{ AT 0 HOUR } & \multicolumn{2}{|c|}{ AT 6 HOUR } & \multicolumn{2}{|c|}{ AT 0 HOUR } & \multicolumn{2}{|c|}{ AT 6 HOUR } \\
\hline & WBC & RBC & WBC & RBC & WBC & RBC & WBC & RBC & WBC & RBC & WBC & $\mathrm{RBC}$ \\
\hline H1 & 1.151 & 0.009 & 0.627 & 0.008 & 1.312 & 0.009 & 0.626 & 0.008 & 0.934 & 0.008 & 0.884 & 0.007 \\
\hline $\mathrm{H} 2$ & 1.125 & 0.009 & 0.644 & 0.008 & 1.197 & 0.008 & 0.912 & 0.008 & 0.965 & 0.008 & 0.897 & 0.008 \\
\hline H3 & 1.142 & 0.008 & 0.623 & 0.009 & 1.193 & 0.008 & 0.989 & 0.008 & 1.032 & 0.007 & 0.994 & 0.008 \\
\hline L1 & 0.062 & 0.000 & 0.183 & 0.000 & 0.077 & 0.000 & 0.194 & 0.000 & 0.063 & 0.000 & 0.144 & 0.000 \\
\hline L2 & 0.059 & 0.000 & 0.082 & 0.000 & 0.082 & 0.000 & 0.191 & 0.000 & 0.088 & 0.000 & 0.127 & 0.000 \\
\hline L3 & 0.071 & 0.000 & 0.086 & 0.000 & 0.069 & 0.000 & 0.201 & 0.000 & 0.099 & 0.000 & 0.142 & 0.000 \\
\hline $\begin{array}{c}\text { CARRY OVER } \\
\%\end{array}$ & -0.008 & 0.000 & 0.180 & 0.000 & -0.055 & 0.000 & -0.008 & 0.000 & -0.038 & 0.000 & 0.002 & 0.000 \\
\hline
\end{tabular}



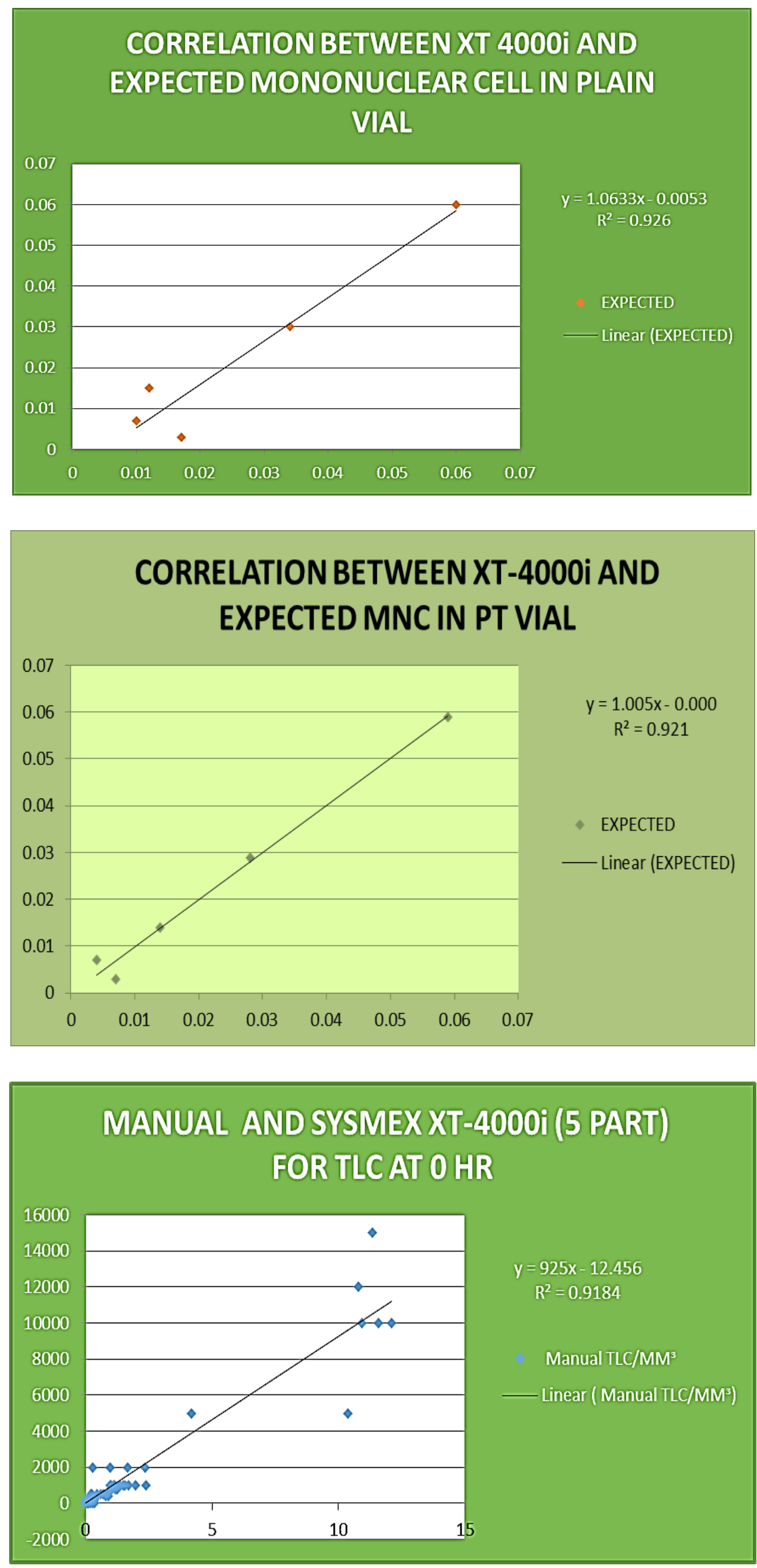


\section{Correlation studies}

A significant positive perfect correlation existed between WBC $\left(/ \mathrm{mm}^{3}\right)$ count measured through Neubauer chamber and Sysmex XT-4000i ( $y=925 x-12.456, r=0.958, p<0.001)$ in plain vial at 0 hour by using Pearson's correlation coefficient. (Fig 3)

For RBC correlation, a ROC curve of RBC count was constructed. The area under curve (AUC) was found to be 0.926 (95\% confidence interval $=0.892$ to 0.960 ). The $P$ value was $<0.05$. This shows a statistically significant difference. The best cut off value for RBC count for predicting RBC Positivity was 0.005 units (Sensitivity $97.4 \%$ and specificity $71.5 \%$, maximum youdan index 0.689) was determined with SE 0.017. (Fig4)

Sysmex XT-4000i showed significant positive correlation for WBC count $(103 / \mu \mathrm{l})$ in plain vial $(r=0.984, p<0.001 \mathrm{~s})$, EDTA vial $(r=0.998, p<0.001 s)$, PT vial $(r=0.958, p<0.001 s)$ at 0 and those kept at $4^{\circ} \mathrm{C}$ at 6 hour. So by keeping the sample at $4^{\circ} \mathrm{C}$ we can increase the shelf life of ascitic fluid. (Table 3 )

TABLE 3: Correlation Of Total WBC Count By Manual Method And Sysmex XT-4000i (5 PART)

\begin{tabular}{|c|c|c|c|c|c|c|c|}
\hline & \multicolumn{6}{|c|}{ SYSMEX XT-4000i } & \multirow{2}{*}{$\begin{array}{l}\text { MANUAL } \\
\text { METHOD }\end{array}$} \\
\hline & \multicolumn{2}{|c|}{ PLAIN VIAL } & \multicolumn{2}{|c|}{ EDTA VIAL } & \multicolumn{2}{|c|}{ PT VIAL } & \\
\hline & 0 HOUR & 6 HOUR & OHOUR & 6 HOUR & 0 HOUR & 6 HOUR & \\
\hline NO. OF & 250 & 249 & 250 & 250 & 246 & 248 & 250 \\
\hline \multicolumn{8}{|l|}{ SAMPLES } \\
\hline MEAN & 0.49 & 0.003 & 0.765 & 0.74 & 0.535 & 0.586 & 445.720 \\
\hline STANDARD & 1.741 & 0.021 & 2.7 & 2.663 & 1.988 & 2.763 & 1680.788 \\
\hline DEVIATION & & & & & & & \\
\hline$r$ & \multicolumn{2}{|c|}{0.984} & \multicolumn{2}{|c|}{0.998} & \multicolumn{2}{|c|}{0.958} & 0.958 \\
\hline R SQUARE & \multicolumn{2}{|c|}{0.968} & \multicolumn{2}{|c|}{0.996} & \multicolumn{2}{|c|}{0.918} & 0.918 \\
\hline P VALUE & \multicolumn{2}{|c|}{$<0.001 S$} & \multicolumn{2}{|c|}{$<0.001 S$} & \multicolumn{2}{|c|}{$<0.001 \mathrm{~S}$} & $<0.001 S$ \\
\hline
\end{tabular}

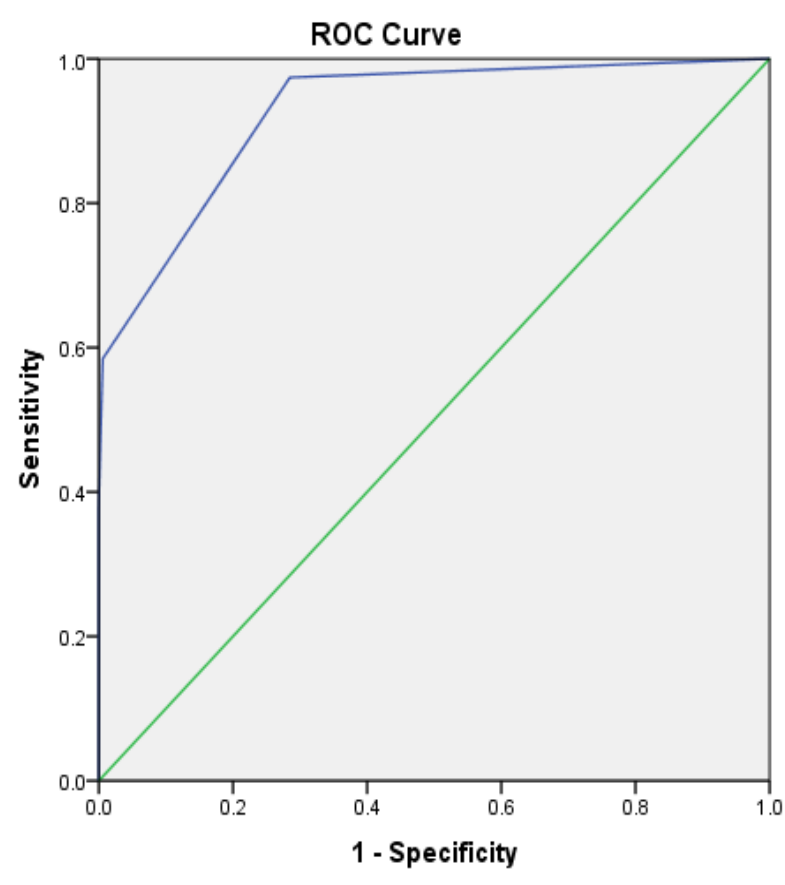

Diagonal segments are produced by ties.

Fig 4: ROC Curve For The Optimal Cut Off Value Of Sysmex XT-4000i (5 Part) For The RBC Count By Manual Method

\section{DISCUSSION}

Laboratory assessments of ascitic fluid is an essential part of disease diagnosis and follow up; therefore accurate and rapid results are very important. ${ }^{3}$

In the present study, chronic liver disease was the most common cause of ascites comprising $94.4 \%$ of cases. The present study included $199(79.6 \%)$ male and $51(20.4 \%)$ female patients. Male to female ratio was $3.9: 1$. In our study cases of ascites were highest in 40 to 49 years age group.
The present study evaluated the performance of the Sysmex XT$4000 \mathrm{i}$ in terms of correlation, precision, carryover and linearity analysis.

For precision analysis the body fluid sample assayed ten times. The precision analysis of random sample with high cell count indicated that the Sysmex XT-4000i demonstrated good precision for RBC, WBC, MN\#, PMN\# at 0 and 6 hour in all vials resulted in CVs $<0.012 \%$.

Results of precision of low cell count were excellent in EDTA vial with CVs being $0 \%$ for RBC, TLC, MN\#, PMN\# at 0 and 6 hour. In the study done by Giuseppe Lippie et $\mathrm{al}^{7}$ the imprecision was excellent, being always lower than $11 \%$.

Our results show negligible carryover between samples with high and low cell counts. The carryover was always lower than $0.180 \%$ for WBC. For RBC carryover results were $0 \%$ in all vials at 0 and 6 hour. To avoid carryover, Sysmex XT-4000i has incorporated an automatic rinse cycle after every measurement. This was corresponding to studies done by Giuseppe Lippi $\mathrm{G}$ et $\mathrm{al}^{8}$ and Buoro $S$ et $\mathrm{al}^{2}$ in which carryover was always lower than $0.2 \%$. Linearity was verified for RBC count, WBC count, MN and PMN by running a fluid five times in dilution. Sysmex XT-4000i presented an excellent correlation between expected and observed values $(r=0.962)$ in plain vial and $(r=0.960)$ in PT vial for MN.

Sysmex XT-4000i showed significant positive correlation for WBC count $\left(10^{3} / \mu \mathrm{l}\right)$ in plain vial $(r=0.984, p<0.001 \mathrm{~s})$, EDTA vial $(r=0.998, p<0.001 s)$, PT vial $(r=0.958, p<0.001 s)$ at 0 and those kept at $4^{\circ} \mathrm{C}$ at 6 hour. So by keeping the sample at $4^{\circ} \mathrm{C}$ we can increase the shelf life of ascitic fluid.

A significant positive perfect correlation existed between WBC $\left(/ \mathrm{mm}^{3}\right)$ count measured through Neubauer chamber and Sysmex XT-4000i ( $y=925 x-12.456, r=0.958, p<0.001)$ in plain vial at 0 hour by using pearson correlation coefficient so plain vial is the best vial for ascitic fluid cell count. This was corresponding to studies done by Kersie $L$ et al $^{9}$ in which Pearson's correlation coefficient for WBC parameter was 0.95 for serous fluid. 
Our study is limited by that we did not find a statistically significant correlation of $\mathrm{MN} \%$ and $\mathrm{PMN} \%$ in all vials between Sysmex XT$4000 \mathrm{i}$ and the Neubauer chamber. This is because of high incidence of macrophages, mesothelial, lymphoid and other tumoral cells in this kind of fluid sample that were not identified by Sysmex XT-4000i. In the study done by Sabrina Buoro et al ${ }^{2}$ showed lack of correlation between MN-BF in Sysmex XE-5000 and lymphocytes in optical microscopy.

Sysmex XT-4000i presented non-significant positive correlation between expected and observed values of RBC,TLC, PMN in all vials.

The results of the present study confirm that the Sysmex XT-4000i exhibits additional advantages over manual microscopy, which are typical of automated flow cytometric analysis and thereby include higher throughout, reduced turnaround time, reduction of sample volume, no need of sample preparation as well as optimal analytical performances. So Sysmex XT-4000i may be reliably used for routine analysis of body fluids.

\section{CONCLUSION}

In conclusion, despite some discrepancies compared to manual chamber count, the Sysmex XT-4000i BF mode is sufficiently accurate, supported by technical reasons such as fully automated sample preparation (i.e, mixing, aspirating, diluting) as well as optimal analytical performances (i.e, extended linearity, acceptable imprecision, low carryover). The Sysmex XT-4000i is not a substitute for manual microscopy; nevertheless it can substantially reduce the number of samples submitted for microscopy.

\section{REFERENCES}

1. Anthony W. Butch, PhD, Porntip K. Wises, David T. Wah, Terrie G. Gornet and Herbert A. Fritsche et al. A multicenter evaluation of the Iris iQ200 automated urine microscopy analyzer body fluids module and comparison with hemacytometer cell counts. Am J Clin Pathol 2008; 129:445-50.

2. Sabrina Buoro, Rosanna Gustinetti, Paola Dominoni, Maria Grazia Alessio, Patrizia Filisetti, Maria Grazia Luca et al. Analytical evaluation of Sysmex UF-1000i for flow cytometric analysis of peritoneal fluid. Clinical biochemistry 2012;45:1263-5.
3. Cherina Fleming, Rob Brouwer, Adriaan van Alphen, Jan Lindemans and Robert de Jonge. UF-1000i: validation of the body fluid mode for counting cells in body fluids. Clin Chem Lab Med 2014;52(12):1781-90.

4. Linda M. Sandhaus. Body fluid cell counts by automated methods. Clin Lab Med 2015;35:93-103.

5. Rua Joaquim Nabuco. Sysmex XT-4000i automated hematology analyzer, 2012.

6. Teanya J. Walker, Lydia D. Nelson, MS, Brian W. Dunphy, MBA, Danna M. Anderson et al. Comparative evaluation of the Iris iQ200 body fluid module with manual hemacytometer count. Am J Clin Pathol 2009;131:333-338.

7. Lippi G, Cattabiani C, Benegiamo A. Evaluation of the fully automated haematological analyzer Sysmex XE-5000 for flow cytometric analysis of peritoneal fluid. J Lab Autom.2013; 18(3):240-4. 8. Lippi G, Cattabiani C, Benegiamo A. Evaluation of WBC count in peritoneal fluid with five different hemocytometers. Clin Biochem. 2013; $46: 173-6$.

9. Kresie $L$, Benavides $A$, Bollinger $P$ Bollinger $P$, Walters $J$, Pierson $D$, Richmond $T$ et al. Performance evaluation of the application of body fluids on the Sysmex XE-2100 series automated hematology analyzer. Lab Hematol 2005; 11: 24-30.

\section{Source of Support: Nil. \\ Conflict of Interest: None Declared.}

Copyright: (c) the author(s) and publisher. IJMRP is an official publication of Ibn Sina Academy of Medieval Medicine \& Sciences, registered in 2001 under Indian Trusts Act, 1882.

This is an open access article distributed under the terms of the Creative Commons Attribution Non-commercial License, which permits unrestricted non-commercial use, distribution, and reproduction in any medium, provided the original work is properly cited.

Cite this article as: Kusum Agrawal, Sandhya Gulati, Gaurav Gupta, Nidhi Sharma, Ajay Yadav. Evaluation of Accuracy of Cell Count in Ascitic Fluid in Automated Cell Counter and Comparison with Manual Count. Int J Med Res Prof. 2016; 2(4):121-26. 